\section{Ventricular Tachycardia}

It is important to distinguish ventricular tachycardia from the other causes of fast heart rate both because of its worse prognosis and because it is treated differently. Unfortunately, it can usually be reliably differentiated only by the electrocardiogram. Ventricular tachycardia is less common than either supraventricular tachycardia or atrial fibrillation, ${ }^{1}$ but when it develops as a complication of acute myocardial infarction there is an increased risk of sudden death from ventricular fibrillation. Ventricular tachycardia is characterized by wide QRS complexes-often of bizarre shape because of their ventricular origin-and slight variations in the $R R$ intervals. Independent $\mathbf{P}$ waves are evidence of the atrioventricular dissociation. Bedside diagnosis is difficult, but, as with the E.C.G. diagnosis, it depends on the recognition of signs resulting from the ventricular origin of the depolarization and from the varying atrioventricular relationship. The patient may have a widely split second heart sound, and he may show cannon "a" waves in the neck veins and variation in the intensity of the first heart sound.

Difficulty may arise in the differential diagnosis when supraventricular paroxysms or atrial flutter occur in a patient with bundle branch block, because the QRS complexes are as wide and bizarre as those of a ventricular tachycardia. Unfortunately, not even the demonstration of independent $P$ waves will clinch the diagnosis of ventricular tachycardia, since these can be produced by a nodal tachycardia with a retrograde atrioventricular block; and if a bundle branch block is also present a ventricular tachycardia may be perfectly mimicked.

A recent paper on this topic ${ }^{2}$ is the latest in a series of publications from the late A. D. Kisten and his colleagues extending over 16 years. They have studied the relationships between the electrical events occurring in the atria and ventricles in episodes of ventricular and atrial tachycardia induced at diagnostic cardiac catheterization. They found that conduction through the atrioventricular node occurs readily in both antegrade and retrograde directions, and that the clinical and electrocardiographic evidence of atrioventricular dissociation is governed entirely by the temporal relationship of the atrial and ventricular depolarizations irrespective of the direction of conduction between the chambers. Unfortunately, there is no evidence to show how often this difficulty in diagnosis may be encountered in everyday cardiological practice. $\mathbf{P}$ waves cannot necessarily be identified in the surface leads, and oesophageal electrodes must be used. However, the only false diagnosis likely to be made from interpretation of the simple standard leads is one of ventricular tachycardia when a supraventricular tachycardia with atrioventricular block is really present, and this misdiagnosis should not lead to inappropriate treatment.

1 Denborough, M. A., Lovell, R. R. H., Nestel, P. J., and Goble, A. J., Lancet, 1968, 1, 386

2 Massumi, R. A., Tawakkol, A. A., and Kisten, A. D., Circulation, 1967, 36, 628 .

- Jewitt, D. E., Kishon, Y., and Thomas, M., Lancet, 1968, 1, 266.

- Gianelly, R., von der Groeben, J. O., Spivack, A. P., and Harrison, D. C., New Engl. f. Med., 1967, 277, 1215. - Spracklen, F. H. N., Kimerling, J. J., Besterman, E. M. M., and

- Katz, M. J., and Zitnik, R. S., Amer. F. Cardiol., 1966, 18, 552.

' Frieden, J., Amer. Heart f., 1967, 74, 283. - Gianelly, R., Griffin, J. R., and Harrison, D. C., Ann. intern. Med.,
1967, 66, 667.
With the increasing recognition of the high incidence of arrhythmias after acute myocardial infarction there have been a number of studies comparing the techniques for their treatment. For ventricular tachycardia there is good evidence that a single, rapid intravenous injection of lignocaine (or "bolus") is effective in a dose of $1-2 \mathrm{mg} . / \mathrm{kg}$. body weight, ${ }^{3-5}$ followed by a continuous infusion of $1-2 \mathrm{mg} . / \mathrm{min}$. This schedule was also used by Dr. M. P. Chopra and his colleagues, who report their findings at p. 213 of this week's B.M.F.

Haemodynamic studies showed that lignocaine in these doses had no adverse circulatory side-effects, though it may produce some drowsiness. Larger doses may give rise to twitching, confusion, stupor, or focal fits. It is contraindicated in both patients with atrioventricular block and a slow rate and those with hepatic dysfunction. The evidence suggests that lignocaine is preferable for the initial treatment of ventricular tachycardia to direct-current cardioversion ${ }^{6}$ and probably also to other drugs in current use such as propranolol, ${ }^{78}$ procainamide, and quinidine. If lignocaine is unsuccessful direct-current cardioversion should then be attempted. Both may be safely used for patients in whom the differential diagnosis between ventricular and supraventricular tachycardia cannot be made. Digitalis is strongly contraindicated in the presence of ventricular tachycardia, an arrhythmia which it may even induce in predisposed individuals. A stable rhythm may not be restored until a low level of serum potassium, often secondary to prolonged diuretic therapy, has been corrected. Hypoxia and acidosis, the twin complications of any acute reduction in cardiac output, must also be recognized and appropriately treated.

\section{A Parasitic Infection}

The filarial worm Acanthocheilonema perstans is widely distributed throughout Africa, South America, and New Guinea. The adult worms have been found in the liver, pleura, pericardium, mesentery, and the perianal and retroperitoneal tissues. The microfilariae are found in the blood throughout the day and are unsheathed. The intermediate vectors in Africa are Culicoides species of "midges." In most persons the infection apparently causes no ill effects. Nevertheless the widely held opinion that $A$. perstans is a harmless parasite is now in some doubt.

It has been pointed out that sometimes this infection does produce clinical illness. ${ }^{1}$ Thus, a tropical-eosinophilia-like syndrome, ${ }^{2}$ calabar swellings, ${ }^{3}$ and neurological and psychic disturbances ${ }^{4}$ have been reported. Rhodesian workers have associated $A$. perstans with the development of arthritis or arthralgia. ${ }^{5}$ More recently they have discovered microfilariae in the cerebrospinal fluid of two patients who developed cerebral symptoms for which no other infective or parasitic cause could be found. ${ }^{6}$ What may be worth further investigation is why the majority of recorded cases of clinical illness due to $A$. perstans have occurred in European patients.

1 Janssens, P. G. D., Ann. Soc. belge Méd. trop., 1964, 44, 989.

2 Gelfand, M., and Bernberg, H., Cent. Afr. F. Med., 1959, 5, 405.

3 Stott, G.. F. trop. Med. Hyg., 1962, 65, 230.

- Adolph, P. E., Kagan, I. G., and McQuay, R. M., Amer. f. trop. Med. Hyg., 1962, 11, 76.

5 Baker, N. M., Baldachin, B. J., Rachman, I., and Thomas, J. E. P., Cent. Afr. f. Med., 1967, 13, 23.

- Dukes, D. C., Gelfand, M., Gadd, K. G., Clarke, V. de V., and Goldsmid, J. M., Cent. Afr. F. Med., 1968, 14, 21. 